\title{
Measurement of The Financial Acceptance for Project of Replacement RTG Engine to RTG Electric
}

\author{
Agung Aryo Wibowo ${ }^{1}$ and Christiono Utomo ${ }^{2}$ \\ ${ }^{1}$ Department of Management Technology, Institut Teknologi Sepuluh Nopember, Surabaya \\ ${ }^{2}$ Department of Civil Engineering, Institut Teknologi Sepuluh Nopember, Surabaya \\ e-mail: agungaryowits@gmail.com
}

\begin{abstract}
Semarang Container Terminal, one of the container terminal operators, wants to prevent growth container throughput with maintaining container loading and unloading services efficiently. Nowadays, technological development can support for the management of loading and unloading activities. Modern technology has created sophisticated equipment to increase port productivity. One of the modern equipments is Automated Rubber Tyred Gantry (ARTG) which uses electricity without an operator cabin. It can be potential savings at operational costs, the fuel/material costs, maintenance costs, and human resource costs. Therefore, Semarang Container Terminal has plan to replace their old RTG (Rubber Tyred Gantry) to ARTG, but the project investment still need to be analyzed for presenting the financial firm impact. This study has analyzed using incremental analysis method compared each alternative. The results presented that ARTG investment was the best alternative. To find out how sensitive the investment parameters influenced a decision, must been analyzed using sensitivity analysis. The final conclusion from this study showed the project of replacement RTG engine to ARTG had been effected by the increased procurement cost by $20 \%$ and the added $9 \%$ from existing tarif.
\end{abstract}

Keywords-ARTG, RTG, Investment Analysis, Incremental, Sensitivity Analysis.

\section{INTRODUCTION}

$\mathrm{T}$ ODAY using of container as transportation has developed in maritime transport. Not only simple packaging with universal standard dimensions, but also great protection to the goods has been the best way for container application. In Indonesia, container throughput significantly increased. Size of container vessels was bigger than before to bring more containers to Indonesia.

Increased the container throuhgput in Indonesia has encouraged Semarang Container Terminal as one of the container terminal operators in Indonesia to develop their facilities. Maintaining container loading and unloading services efficiently was the important thing to improve. One element which can be developed is loading and unloading equipment. Today technology development has led to sophisticated equipment to increase productivity at the port.

Abdel-Fattah, et al (2013) generally described container terminal layouts which have some equipments which used for container loading and unloading operational activities. The type of equipment was divided into three sections based on its location namely quayside, yard and gate as described in Figure 1. The Semarang Container Terminal has Container Crane (CC) on the quayside side and Rubber Tyred Gantry
(RTG), Automated Rubber Tyred Gantry (ARTG), Reach Stacker (RS) and Side Loader (SL) on the yard side.

From some of the equipments above, the ones using electrical power supply are CC and ARTG, while FE used batteries. Other equipment has used petrol.

Rubber Tyred Gantry (RTG) is one of the container equipments that operates in the stacking yard. The types of RTG have been used in the Semarang Container Terminal as follows :

1. RTG Engine : RTG used diesel engine as main power supply.

2. Automated RTG (ARTG) : RTG used electric as main power supply, without operator and controlled at control room that separate away with the crane.

The difference between both of RTG is the source of energy and technology. Electric power supply and new technology have a significant impact on operational costs, cost of materials (fuel and electricity), maintenance costs, and cost of human resources (HR). An operator can operate 4 - 6 ARTG units automatically. Yang and Chang (2013) has explained that the use of electric RTG shows an energy savings of $86.60 \%$.

Related to replace RTG Engine to ARTG, it is necessary to analyze for the investment to know profitable for the company. ARTG is more expensive than RTG engine. Looking from operational perspective, using ARTG is more efficient in productivity. The main resources of ARTG have already used electricity which is cheaper energy and more green. Yang and Chang (2013) has showed RTG electric could reduce $67.79 \%$ in $\mathrm{CO}_{2}$ emissions. Therefore, this study discussed the measurement of financial acceptance for project of replacement RTG engine to ARTG at Semarang Container Terminal. The financial acceptance are investment costs, revenue, and operating costs that can affect the acceptance of the investment project.

\section{METHOD}

This paper is a financial modeling study to obtain the financial acceptance of loading and unloading equipment investment using incremental and sensitivity analysis in a case study at the Semarang Container Terminal. The research process can be shown in Figure 2 .

Several studies have used NPV, IRR, PP, PI, and BCR methods to make an investment project decision. Rachadian et al (2013) used NPV, PP, and PI for comparing investment alternatives. The result showed that the alternative 
The $1^{\text {st }}$ International Conference on Business and Engineering Management (IConBEM)

February $1^{\text {st }} 2020$, Institut Teknologi Sepuluh Nopember, Surabaya, Indonesia

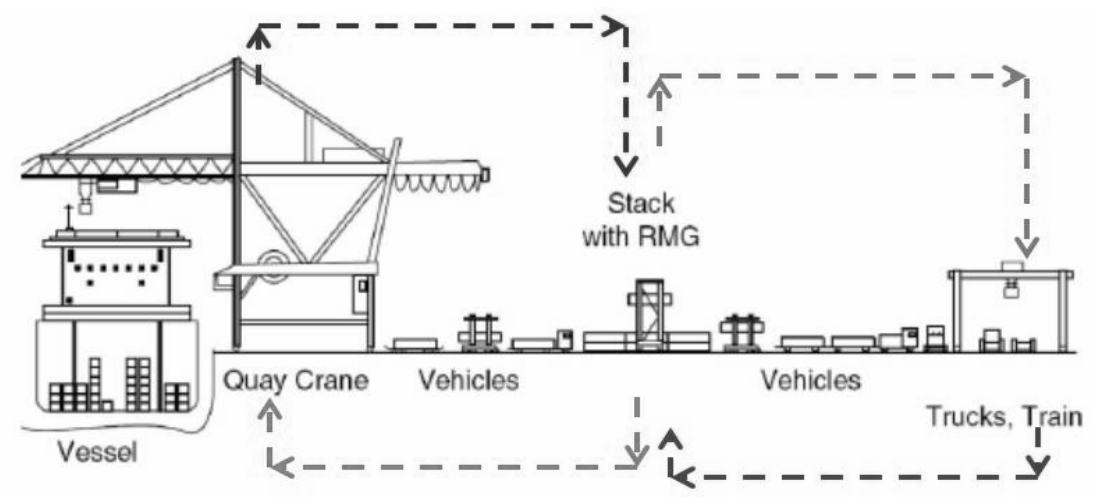

\section{Quayside Yard $\quad$ Gate}

Figure 1. General Layout of Container Terminal [1] Source : Abdel-Fattah, dkk (2013)

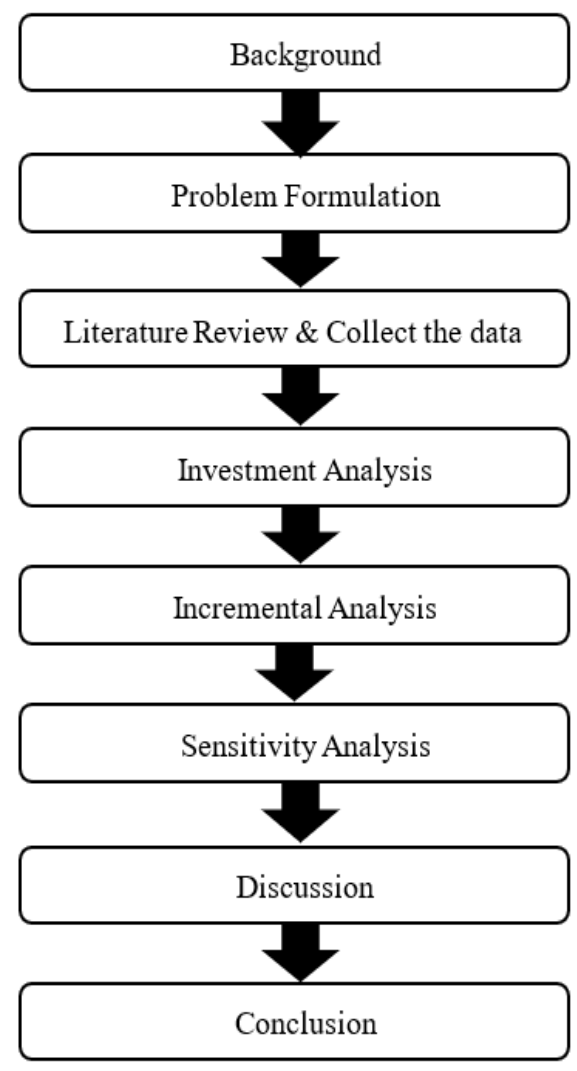

Figure 2. Research process

replacement of damaged components was better than the added a new milling machine in 10 years.

Rumiyanto et al (2015) has analyzed using NPV, IRR, and PP methods. The result was the two investment alternatives being feasible. To obtaine the best alternative, an incremental was performed that the alternative $\mathrm{B}$ (challenger) or Columbus Ergostar Exa 4000 CNC ESAB machine was better than alternative A (defender) or the CNC Honey Bee Hypertherm machine.

Not only used investment analysis, but also some researches used sensitivity analysis to find out how sensitive an investment project decision which is influenced by the factors or parameters. Rianto et al (2018) used sensitivity analysis which was effected by alternatives fuel prices, dollar exchanged, and decreased gas rates. The study has concluded that the requirement to set the investment decision.
This paper explained some analysis was described on the previous paragraph. The methods which used are :

1. Investment analysis

The tool is used to analyze the estimated cash inflow and outflow during the life investment. For example cash flow can be shown in Figure 3. Cash flow is formed from investment variables that are :

a. Investment cost: estimated procurement cost of RTG and ARTG, estimated electric power supply and IT (Information Technology) network instalation for supporting the ARTG operation.

b. Investment period: life cycle equipment.

c. Rate of Return: estimated rate of return using consideration of the average deposit interest of banks in Indonesia and the company's capital costs.

d. Financing: composition of company capital and bank loan.

e. Inflow: estimated revenue of RTG and ARTG production.

f. Outflow: estimated human resources costs, resources (fuel and electricity) costs, and maintenance costs.

g. Salvage value: estimated value in the end of life cycle equipment.

Pujawan (2009) explained that an estimated of cash flow must always considered the predictions of future conditions as well as attention to trends described by the past. After determining the cash flow, the next step was to set the Minimum Attractive Rate of Return (MARR) as the basic value for evaluating. The results are compared according to investment criteria, as follows :

a. Net Present Value (NPV) : the project can be accepted if $\mathrm{NPV}$ is more than zero (NPV $>0$ ).

b. Internal Rate of Return (IRR) : This method is needed to show the project is accepted or not, looked by the return flow. The internal rate of return is formulated as a discount rate which makes NPV $=0$.

2. Incremental analysis

Incremental analysis is the next step of investment analysis if there are more than one alternative available and need to determine alternative ranking/priority. This analysis has obtained the best alternative [2]. Provisional ranking is based on the smaller investment to the other investment. In this study, it was sorted from "do nothing", RTG investment and 


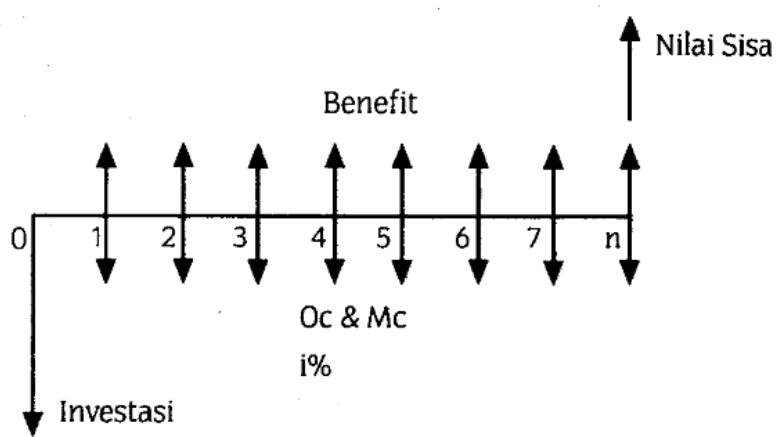

Figure 3. Example for investment cash flow [1].

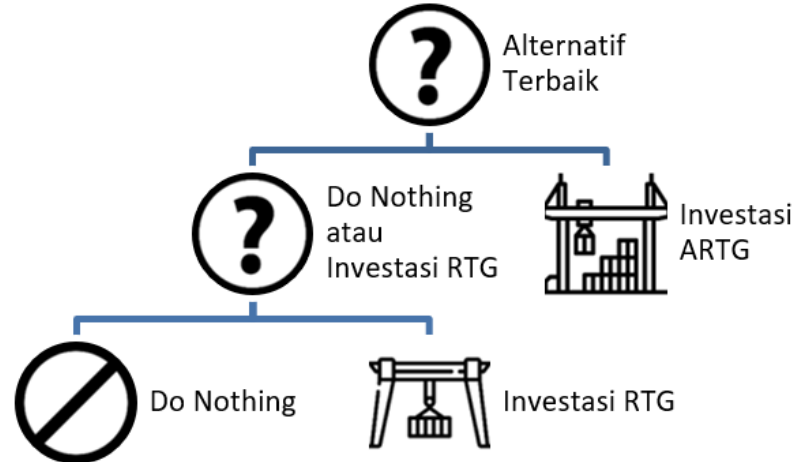

Figure 4. Alternative Patterns "Do Nothing", RTG, and ARTG

ARTG investment. The smallest investment (temporary best) is called a defender, the next best is called a challenger, while the best compared is called a winner. The first stage did incremental analysis between "do nothing" and RTG investment. The second phase is carried out incrementally between the results of the first stage with ARTG investments. In the next stage, the best alternative is obtained. The detail can be shown in Figure 4. From these alternatives an analysis is carried out to get how sensitive to the parameters that can influence it.

\section{Sensitivity analysis}

In financial investment analysis, the determined variables can be without the errors. The variables are still an assumption so that requires sensitivity analysis. The analysis is displayed on the sensitivity graph. NPV and IRR is calculated on each change of the investment variables.

After being chosen in incremental analysis, a sensitivity analysis is carried out on the increased procurement costs of loading and unloading equipment and tarif. The change of equipment procurement costs and tarif rates are plotted in the graph. After plotted in the graph, each variables can be seen how much the limits of acceptance to do an investment.

\section{RESULTS AND DISCUSSION}

\section{A. Investment Cost}

In this study, investment cost was the cost of loading and unloading equipment (RTG and ARTG) procurement. Moghadan and Noori (2011) have explained that procurement costs depend on some factors including :

1. Procurement period

The period of procurement of cranes in the study is 1 year. The time has included schedule for the design phase, manufacturing, shipping, assembly phase, and testing.

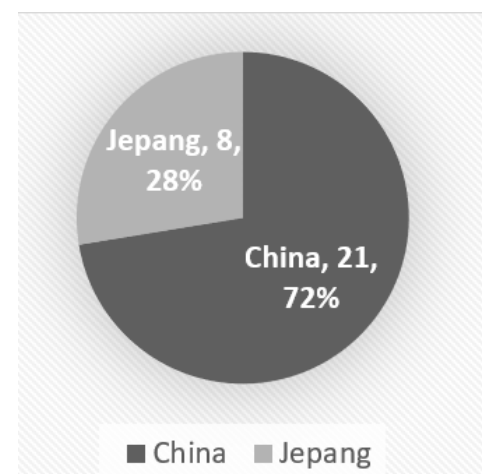

Figure 5. Alternative Patterns "Do Nothing", RTG, and ARTG

Table 1.

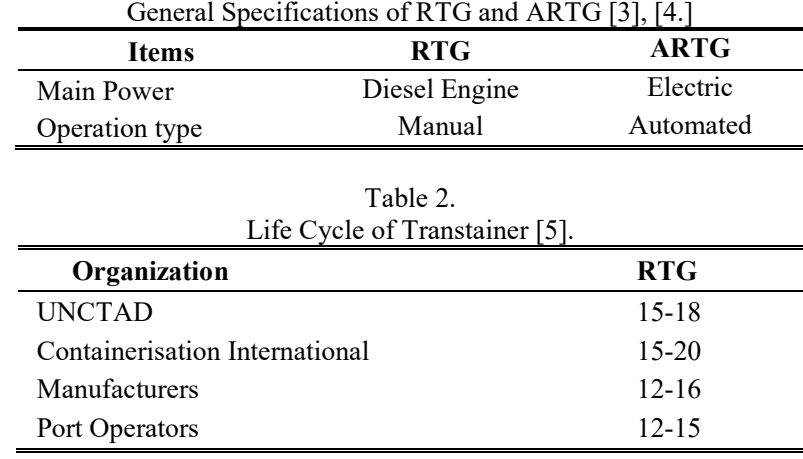

2. Amount of procurement

The number of RTG or ARTG procurement is 3 units to be operated in 3 stacking blocks.

3. Manufacturing location

Based on secondary data, the population of crane manufacturing countries in Semarang Container Terminal is China and Japan with the data shown in Figure 5. The graph showed that 21 units of existing cranes made by Chinese manufacturers and 8 units of existing cranes produced by Japanese manufacturers. So, all existing cranes were manufactured by manufacturers in Asia.

4. Crane specifications

Crane specifications have depend on the needs of the container terminal. In general, the differences specifications between RTG and ARTG can be presented in Table 1.

RTG used the diesel engine as the main power source and operated manually, which means that one crane required one operator for handling in the operator cabin which located on the crane unit.

ARTG used electricity as the main power supply and operated automatically which one operator can controlled 46 unit cranes. Operator handled the crane on the operator's room (control room) that separated to the unit cranes. So, the cranes were controlled remotely far away from the cranes location.

\section{Variations in market prices}

Development of technology has support the crane manufacturers created various types. In this study, RTG and ARTG have the same types with existing equipment. It was 1 over 5 as shown in Figure 6. The picture has displayed containers that can be stacked with a maximum height of 5 tiers and one tier was used for container movements, and container width was 6 rows. 


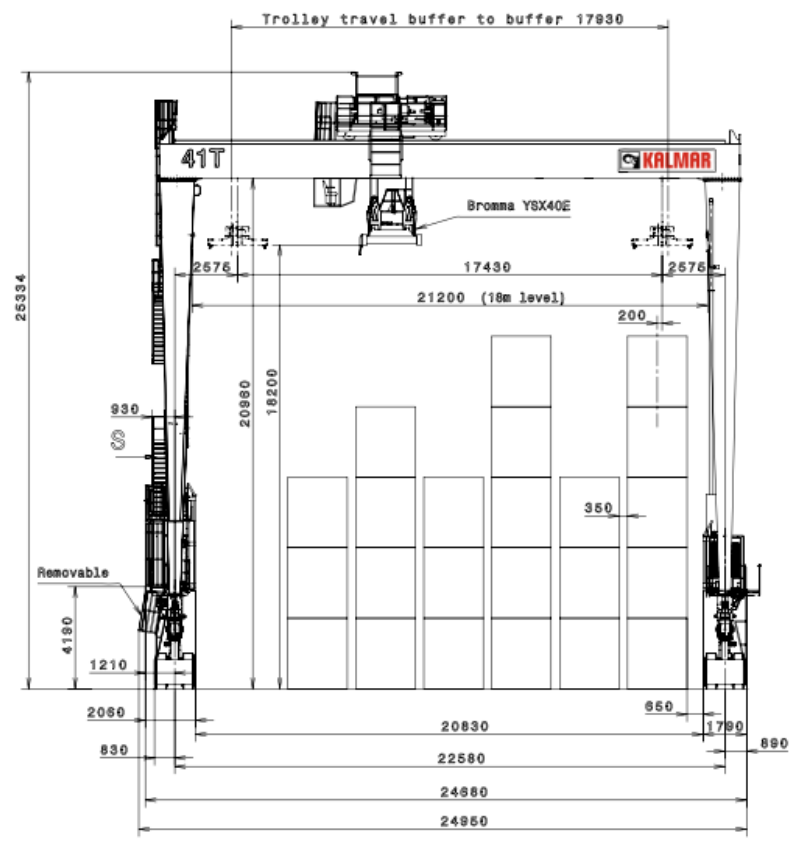

Figure 6. Existing RTG (1 over 5 type) Source : Operator's Manual Book RTG, 2012

Table 3.

Human Resources Needed

\begin{tabular}{lccc}
\hline \hline Equipment & $\begin{array}{c}\text { Crane } \\
\text { (unit) }\end{array}$ & $\begin{array}{c}\text { Operator Crane } \\
\text { (person) }\end{array}$ & $\begin{array}{c}\text { Tally Officer } \\
\text { (person) }\end{array}$ \\
\hline RTG & 3 & 12 & 12 \\
ARTG & 3 & 4 & 0 \\
\hline \hline
\end{tabular}

\section{B. Investment Period}

The investment period in this study has used the life cycle of loading and unloading equipment in the container yard (RTG and ARTG).

In general, the life cycle of the equipment which operated in the stacking yard was determined by manufacturer calculating the crane operating cycles. Life cycle can also be determined in the technical spesifications regarding to the port needs when the procurement has been processing.

In operation, several factors that affected the life of crane included the utilization, maintenance activities, operator skills when operating the crane, and the surrounding environment. Moghadam and Noori (2011) have stated that the average economic life of loading and unloading equipment in the stacking yard has differences from some sources. There were United Nations Conference on Trade and Development (UNCTAD), Containerisation International, manufacturer, and port operator terminals as shown in Table 2. The accounting policy of PT Pelabuhan Indonesia I, II, III, IV (Persero) in 2011 stated that the economic life of transtainer was 12 years. So, in this paper, replacement the RTG engine to RTG electric project has used 12 years as an investment period.

\section{Inflow}

For the yard side, the port services are divided into 2 types of rate were container stacking rate and lift on lift off rate. In this study, the project has been related to lift on lift off rates.

The Government of Indonesia have stipulated somethings that became constraints in determining the port service tarif, as follows :
Table 4

Incremental of "do nothing" and RTG

\begin{tabular}{|c|c|c|c|c|c|}
\hline Year & \multicolumn{2}{|c|}{ Net Cash Flow } & $\begin{array}{l}\text { Discount } \\
\text { Factor }\end{array}$ & & $\begin{array}{l}\text { ounted Cash } \\
\text { Flow }\end{array}$ \\
\hline 0 & \multicolumn{2}{|c|}{$\operatorname{Rp}(66,639,097,800)$} & 1.00000000 & \multicolumn{2}{|c|}{$\operatorname{Rp}(66,639,097,800)$} \\
\hline 1 & $\mathrm{Rp}$ & $7,811,504,991$ & 0.90449852 & $\mathrm{Rp}$ & $7,065,494,730$ \\
\hline 2 & $\mathrm{Rp}$ & $7,262,985,283$ & 0.81811758 & $\mathrm{Rp}$ & $5,941,975,935$ \\
\hline 3 & $\mathrm{Rp}$ & $8,982,242,928$ & 0.73998614 & $\mathrm{Rp}$ & $6,646,735,291$ \\
\hline 4 & $\mathrm{Rp}$ & $8,350,547,138$ & 0.66931637 & $\mathrm{Rp}$ & $5,589,157,921$ \\
\hline 5 & $\mathrm{Rp}$ & $10,455,523,740$ & 0.60539567 & $\mathrm{Rp}$ & $6,329,728,809$ \\
\hline 6 & $\mathrm{Rp}$ & $9,698,374,536$ & 0.54757949 & $\mathrm{Rp}$ & $5,310,630,986$ \\
\hline 7 & $\mathrm{Rp}$ & $12,243,472,538$ & 0.49528484 & $\mathrm{Rp}$ & $6,064,006,343$ \\
\hline 8 & $\mathrm{Rp}$ & $11,301,661,834$ & 0.44798441 & $\mathrm{Rp}$ & $5,062,968,274$ \\
\hline 9 & $\mathrm{Rp}$ & $14,344,187,813$ & 0.40520123 & $\mathrm{Rp}$ & $5,812,282,610$ \\
\hline 10 & $\mathrm{Rp}$ & $13,135,432,296$ & 0.36650392 & $\mathrm{Rp}$ & $4,814,187,405$ \\
\hline 11 & $\mathrm{Rp}$ & $16,733,484,932$ & 0.33150225 & $\mathrm{Rp}$ & $5,547,187,954$ \\
\hline \multirow[t]{3}{*}{12} & $\mathrm{Rp}$ & $15,144,160,724$ & 0.29984330 & $\mathrm{Rp}$ & $4,540,875,101$ \\
\hline & & & NPV & $\mathbf{R p}$ & $2,086,133,566$ \\
\hline & & & IRR & & $11.12 \%$ \\
\hline
\end{tabular}

1. The port service tarif is determined by the minister of transportation, which was previously socialized and agreed between the port and the association.

2. The port services tarif was determined to have the highest margin at the cost of production plus a maximum profit margin of $25 \%$ of the cost per unit of port services.

3. The port service tarif can be reviewed at least once every two years, except for an increased the inflation rate equal to or greater than $7 \%$, an increased services, an increased the port infrastructure, and an extraordinary situation/force majeure.

So, it concluded that the port service tarif was very difficult to predict the increasing in the future. Regarding to the secondary data obtained, container handling rates in Semarang Container Terminal have not changed since 2013. Therefore, the project of replacement RTG engine to RTG electric has used comparative analysis. The analysis was carried out to obtain the approach needed to determine tarif increased. The lift on lift off rates at several container terminals in Indonesia estimated to increase $11.01 \%$ of existing rate every 2 years.

This paper used data production of loading and unloading equipment on 3 stacking blocks. Data production was separated based on the size of the container including 20 feet, 40 feet, and 45 feet for full container and 20 feet, 40 feet, and 45 feet for empty container.

For the estimation of investment period, an approach was made to increase the container terminal production as presented in Figure 7. The estimation method used the linear regression trend method which was calculated by a spreadsheet. The result of calculation was the average production increased per year is $4 \%$.

\section{Outflow}

Winarno, et al (2019) explained that the used of ARTG in Semarang Container Terminal had reduced needs of crane operators. It has an impact on the cost of human resources can be a savings on operational costs. 
The $1^{\text {st }}$ International Conference on Business and Engineering Management (IConBEM)

February $1^{\text {st }} 2020$, Institut Teknologi Sepuluh Nopember, Surabaya, Indonesia

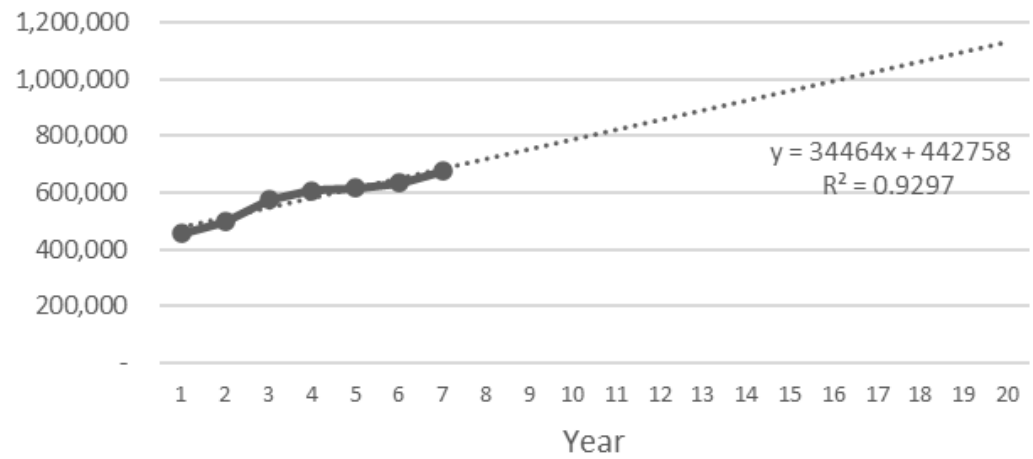

Figure 7. Production Regression Forecast for 12 Years (TEUs)

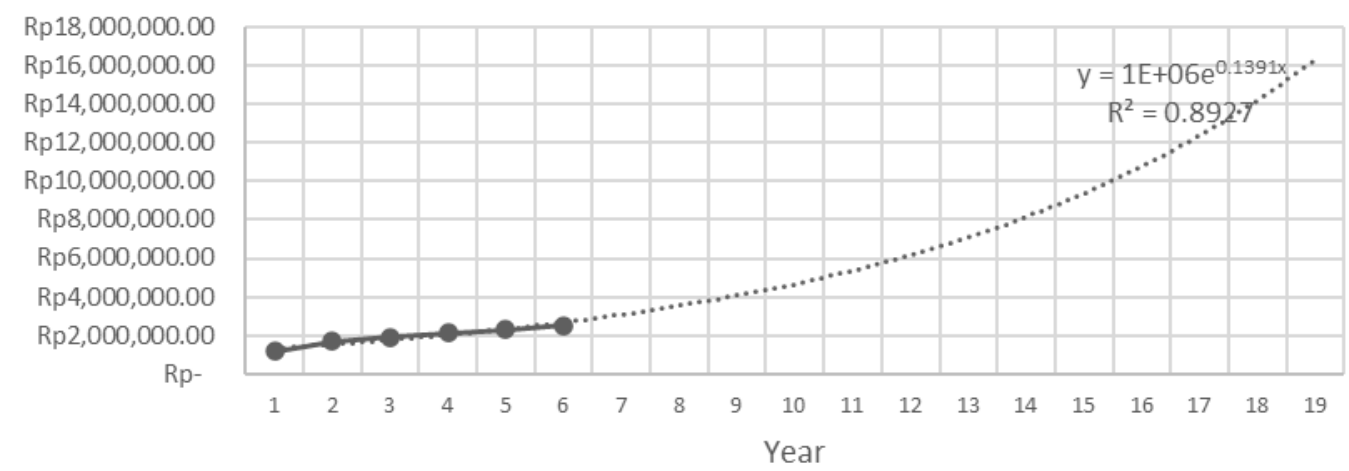

Figure 8. Salary Regression Forecast for 12 Years.

Table 5.

Incremental of RTG and ARTG

\begin{tabular}{|c|c|c|c|}
\hline Year & Net Cash Flow & $\begin{array}{l}\text { Discount } \\
\text { Factor }\end{array}$ & $\begin{array}{l}\text { Discounted Cash } \\
\text { Flow }\end{array}$ \\
\hline 0 & $\operatorname{Rp}(56,773,436,714)$ & 1,000000000 & $\operatorname{Rp}(56,773,436,714)$ \\
\hline 1 & Rp $\quad 6,352,312,811$ & 0,904498523 & $\operatorname{Rp} \quad 5,745,657,557$ \\
\hline 2 & Rp $7,176,314,419$ & 0,818117579 & Rp $\quad 5,871,068,977$ \\
\hline 3 & Rp $8,499,356,237$ & 0,739986142 & Rp $\quad 6,289,405,832$ \\
\hline 4 & Rp $\quad 9,446,662,530$ & 0,669316373 & Rp $\quad 6,322,805,899$ \\
\hline 5 & Rp $11,003,290,131$ & 0,605395671 & $\operatorname{Rp} \quad 6,661,344,211$ \\
\hline 6 & Rp $12,109,878,572$ & 0,547579490 & $\operatorname{Rp} \quad 6,631,121,137$ \\
\hline 7 & Rp $13,961,126,131$ & 0,495284841 & Rp $\quad 6,914,734,129$ \\
\hline 8 & Rp $15,273,808,567$ & 0,447984407 & Rp $\quad 6,842,428,072$ \\
\hline 9 & Rp $17,497,438,651$ & 0,405201235 & Rp $\quad 7,089,983,743$ \\
\hline 10 & Rp $19,077,193,577$ & 0,366503918 & $\operatorname{Rp} \quad 6,991,866,197$ \\
\hline 11 & Rp $21,772,473,531$ & 0,331502253 & Rp $\quad 7,217,624,028$ \\
\hline \multirow[t]{3}{*}{12} & Rp $23,698,817,830$ & 0,299843298 & Rp $\quad 7,105,931,704$ \\
\hline & & NPV & Rp $22,910,534,777$ \\
\hline & & IRR & $16.55 \%$ \\
\hline
\end{tabular}

Teluk Lamong Terminal, which has the same business as the Semarang Container Terminal, has used an Automated Stacking Crane (ASC) which similar to RTG. The difference was ASC did not need the operator on the crane but it could be controlled in control room that similar to ARTG. Silalahi, et al (2016) explained that ASC could provide solutions for the high cost of operators salary.

In this study, there were human resource costs consisting of crane operators salary and tally officers salary. The responsibility of the crane operator was to operate the crane and have met the requirements of the certification. The tally officer has the duty to check the containers based on the operation plan.
Table 6.

Sensitivity Table of NPV against increased ARTG procurement costs

\begin{tabular}{cc}
\hline \hline Increased Procurement Cost & NPV \\
\hline $5 \%$ & Rp. 17,690,894,741 \\
$10 \%$ & Rp. 11,672,913,747 \\
$15 \%$ & Rp. $5,654,932,753$ \\
$20 \%$ & Rp. $(363,048.241)$ \\
$25 \%$ & Rp. $(6,381,029,235)$ \\
\hline \hline
\end{tabular}

Table 7 .

Sensitivity Table of NPV against changed tarif

\begin{tabular}{ccc}
\hline \hline Changed Tarif & \multicolumn{2}{c}{ NPV } \\
\hline $12 \%$ & Rp. & $21,299,417,680$ \\
$11 \%$ & Rp. & $14,675,415,946$ \\
$10 \%$ & Rp. & $8,245,046,068$ \\
$9 \%$ & Rp. & $2,003,168,385$ \\
$8 \%$ & Rp. & $(4,055,246,640)$ \\
\hline \hline
\end{tabular}

For the RTG unit, each crane was operated by one operator with the assistance of one tally officer. For the ARTG unit, 46 units equipment could be operated by one operator without tally officer assistance because the operation plan was included in a container terminal operating system that can managed and recorded every movement of containers in the stacking yard. In determining the number of people it is necessary to consider that Semarang Container Terminal served 24 hours non-stop, which applied three shifts for operational officers so that in one group there are 4 people. The total HR needs for 3 RTG units are 24 people and for 3 ARTG units there are $4 \mathrm{HR}$ people. Human resource needs can be presented in Table 3.

For salary levels, RTG and ARTG operators have the same amount. Salary increases in the following years are calculated from increases in the regional minimum average in the city of Semarang. Dewi et al. (2018) has explained that to calculate 
The $1^{\text {st }}$ International Conference on Business and Engineering Management (IConBEM)

February $1^{\text {st }} 2020$, Institut Teknologi Sepuluh Nopember, Surabaya, Indonesia

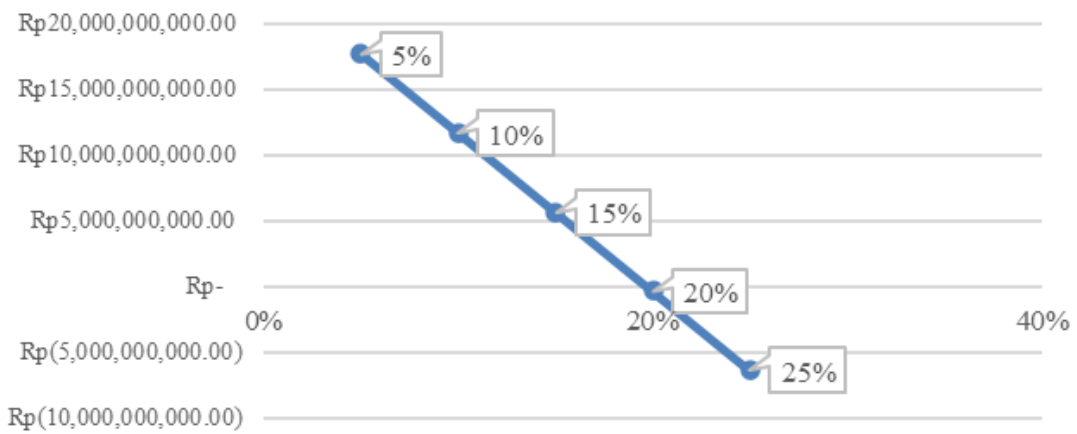

Figure 9. Sensitivity Graph of Increased ARTG Procurement Cost.

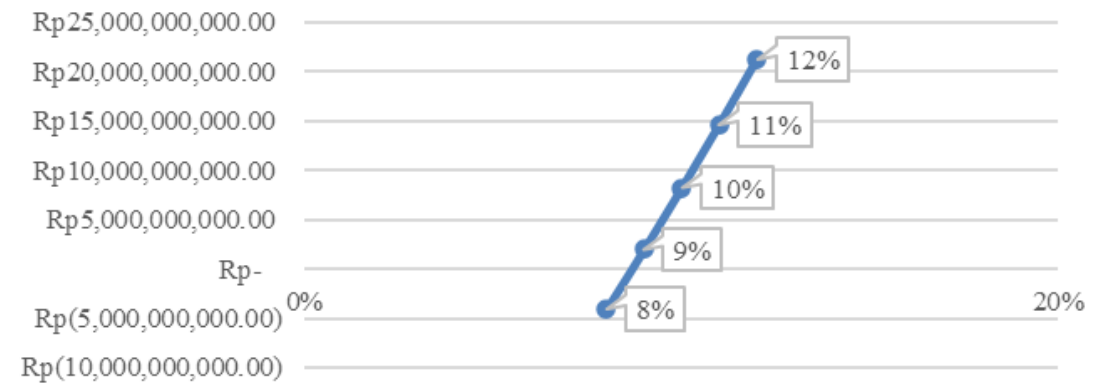

Figure 10. Sensitivity Graph of Changed Tarif

salary based on years of service using an exponential function. From the literature review, the forecast increase in the size of the UMR in Semarang uses a simple exponential regression analysis. The calculation results obtained an increase of $14.92 \%$ per year to calculate the amount of crane operator salaries and tally officers salaries over the next 12 years as shown in Figure 8.

\section{E. Analysis \& The Results}

The first research objective is to determined the acceptance of replacement RTG engine to RTG electric using the incremental analysis of "do nothing", RTG investment and ARTG investment. The results of the study was concluded as follows :

1. The first step analyzed incremental of "do nothing" and RTG investment. The results were NPV Rp. 2,086,133,566 and IRR $11.12 \%$ with MARR $10.56 \%$. Calculations can be displayed in Table 4. From these results, the conclusion was RTG investment the best alternative temporarily.

2. From the results of the first step, the next stage has analyzed incremental of RTG investment and ARTG investment. The results were NPV Rp. 22,910,534,777 and IRR $16.55 \%$ with MARR $10.56 \%$ that shown in Table 5. The results explained that ARTG investment is the best alternative of several alternatives compared

Related to the project replacement RTG engine to ARTG, the procurement costs of ARTG which is more expensive than RTG was profitable for the company.

The second research objective is to obtained financial acceptance on the replacement RTG engine to RTG electric. The results of the study was concluded, namely :
1. The results showed that every $5 \%$ increased procurement cost of equipment can have a negative impact on the change in the NPV. A sensitivity analysis on ARTG procurement cost at a $20 \%$ can be unacceptable as shown in Table 6. To see how sensitive the effect of changed tarif can be displayed in Figure 9. The graph has explained that the higher ARTG procurement cost from the initial assumptions effected the NPV more negative. By using interpolation, the maximum limit for the increased procurement cost of ARTG was $19.6983 \%$.

2. Sensitivity analysis on changed tarif showed that every $1 \%$ tarif can have a negative impact on NPV changes. The smaller changed tarif can be unacceptable investement of ARTG. The $8 \%$ increase in tariffs from the current rate has resulted in the procurement of ARTG being unacceptable as shown in Table 7. To see how sensitive the effect of changed tarif can be displayed in Figure 10.

\section{REFERENCES}

A. K. Abdel-Fattah, A. B. ElTawil, and N. A. Harraz, "An integrated operational research and system dynamics approach for planning decisions in container terminals," 2013.

[2] M. Giatman, Ekonomi Teknik. Jakarta, Indonesia: Raja Grafindo Persada, 2011.

[3] Kalmar, Maintenance Manual RTG. Cargotec Finland Oy, 2012.

[4] Konecranes, Maintenance Manual ARTG. Konecranes Global Corporation, 2017.

[5] M. M. Kiani and R. Noori, "Cost function modelling for semiautomated SC, RTG and automated and semi-automated RMG container yard operating systems," 2011. 